\title{
Youngmi Kim
}

\section{Reflections of Reality in the Literary Fiction of Multilingual Authors}

\begin{abstract}
There are many authors whose literary works are deeply marked by their linguistic ability; most of them have multicultural backgrounds and are familiar with multilingual environments. The sense of multicultural society and possible cultural conflicts is often to be seen in the works of multilingual authors. One such author is Anna Kazumi Stahl: she was born to a Japanese mother and a German-American father and is based in Argentina. She has worked mainly in Spanish, and her first novel, Flores de un sólo día, is written in Spanish. In this novel, the protagonists are confronted with issues concerning the multicultural background of the family. Elif Shafak is a French-born Turkish writer and writes in Turkish and English. Her Forty Rules of Love describes a story with multiple storylines, one of which shows an exotic landscape in Baghdad. Another storyline is narrated by the unhappy Jewish housewife Ella. The analysis of those two fictional works will discuss themes such as multicultural and multilingual contexts, and highlight the connection between culture, language, and identity.
\end{abstract}

Keywords: autobiographical novel, culture, identity, language, multilingualism

\section{Introduction}

One of the main characteristics of the global world is the increasing appearance of multiculturalism in daily life. When taking a closer look at the reflection of multiculturalism in modern literature, we are inevitably confronted with the deep connection between culture and language, since a majority of the global population is embedded in a multicultural society where many different languages are spoken simultaneously.

This reflection of reality in terms of a multilingual environment in literary fiction is also visible in certain literary works of authors such as Anna Kazumi Stahl and Elif Shafak, despite their different personal backgrounds and writing styles. Anna Kazumi Stahl, who was part of a multilingual environment through her US father and Japanese mother, left her birthplace, the US, and went to Buenos Aires in her mid-twenties. Fleurs d'un jour (2005) was written by Stahl after she learned Spanish, the language of her new surroundings. The original edition, which is written in Spanish, was published under the title Flores de un 
solo dia (2002). ${ }^{9}$ The autobiographical aspects are strongly represented in her novel through the protagonist Aimée Levrier, who lives in Buenos Aires with her mute Japanese mother Hanako after the mother and daughter have abruptly left the US.

Elif Shafak is a Turkish writer whose work has been translated into about fifty languages. Her novel The Forty Rules of Love is differentiated from Stahl's work where autobiographical connections are concerned, since Shafak's protagonist, Ella Rubinstein, is a Jewish-American woman and does not show any similarities to Shafak, who writes in English and Turkish, and was born in France, raised in Turkey, and educated in Spain before settling in the US. Despite the absence of parallels between the author and the protagonist, Shafak's perception of the global world in terms of the diversity of multilingual culture is reflected in Ella's revelation when she encounters the manuscript for a book called Sweet Blasphemy. The manuscript, which is about the thirteenth-century Sufi poet Rumi and Shams of Tabriz, enables Ella to see a clear connection between her own life and the fictional story, though she does not have any knowledge of Sufi or the poet Rumi. Elif Shafak did not create a protagonist who shares her personal background, but her cosmopolitan worldview is reflected in Ella, who slowly changes through her encounter with the lessons in Sweet Blasphemy.

The main purpose of this article is to examine the similarities and differences between the protagonists in Fleurs d'un jour and The Forty Rules of Love; the analysis focuses on the connection between culture, language, and identity in these literary works. Homi K. Bhabha, with his concept of hybridization, argues that the present situation is unavoidably influenced by the past in guises such as colonialism. Since the encounter between many different cultural ideas creates multiculturalism, it is essential to understand the historical context to gain insight into the interdependence between individual, culture, and nation.

Stahl and Shafak are both women with multilingual and multicultural backgrounds who deal with today's multicultural world and its influence on individuals. The main goal of this paper is to seek an answer to the following questions:

(1) Are the protagonists created by Stahl and Shafak more influenced by their cultural heritage or their sense of individuality?

(2) Does language play an essential role in identity formation? And, if the answer is yes, is cultural integration possible without mastering a language?

(3) Finally, are there any crucial similarities or differences between Stahl and Shafak regarding their approach to defining the relationship between culture, identity, and language? One of the interesting facts is that both of them write in

9 The English edition was out of print; the French edition is used in this paper instead. 
languages which are not their mother tongue. Shafak's choice to write in English looks quite reasonable at first sight because she was born in France and her father worked as a diplomat. Although she also spent many years in Turkey as a teenager, Shafak's educational background, including her university degree obtained in an English-speaking country, leads to the assumption that she had to master English at a certain point for many different reasons. But Stahl, who is a native of Louisiana and came to Argentina, did not know a single word in Spanish at first. She was twenty-four when she started learning Spanish without any visible personal connection to the country or the language, as a half-Japanese from Louisiana whose father had German ancestors. It is clear that literary analysis does not always lead to knowledge of Stahl's personal motivation; the latter will be one of the interesting factors to consider in this article.

\section{Language and identity}

\subsection{Art as a language tool}

In Fleurs d'un jour, Aimée and her mother Hanako live in Argentina and run a store named Hanako Fleurs, which represents the traditional Japanese art of ikebana by creating and selling arranged flowers. Aimée, the daughter, does not seem very attached to Japanese culture, since it was not the dominant part of her life in Argentina or in the US, where she spent several years of her life before leaving for Buenos Aires. She is also acquainted with Javier Nakamura and his mother; Javier is a third generation Japanese-Argentinian and does not play any essential role for Aimée where their common cultural background is concerned. Neither the Nakamura family nor Aimée's mute mother Hanako, who suffers from agoraphobia, helps Aimée to grasp her identity as a half-Japanese.

In these circumstances, Aimée's dedication to ikebana does not show any obvious relationship between her and flower arrangement, but the following characteristic of ikebana makes that relationship visible: "le chagrin, la joie, le désir et les emotions qui prédominent chez son créateur ou son entourage" (Stahl 2005, 49). Ikebana has its origins in Buddhism in Japan and distinguishes itself mostly from a symmetric Western flower arrangement style through its asymmetry, which reflects a connection between humans and nature (Moriyama and Moriyama 1999, 357). Aimée may appear as a protagonist without any strong characteristics in readers' eyes at first, but she expresses herself more in flower arrangement than in interpersonal communication. Since ikebana also reflects part of the emotions and inner thoughts of the artist, it enables Aimée to realize 
that she is also personifying an asymmetric relationship between herself and her environment through her personal history. Although she hardly identifies herself as US or Japanese, the presence of her Japanese mother, and even the flower shop, distinguish her from other Argentinians. Aimée may feel that the Japanese flower arrangements resemble her asymmetric inner life, which is not to be interpreted as negative, but just as different from others who are more interested in a cheerful life and its symmetry. For her and her silent mother Hanako, ikebana is one of the languages they use to express themselves and to communicate. This communicative role of ikebana becomes especially significant for Hanako when an arrangement of twisted black pyracantha branches shows an upcoming danger through the scribbles on the attached paper bow and presents itself as a counterpart to a letter that has arrived containing a family secret (Aizenberg 2005, 210). The paper bow represents the words in the letter from the US, which threatens the small domestic world of Hanako.

Similarly, in The Forty Rules of Love, the main character, Ella Rubinstein, sees in a manuscript named Sweet Blasphemy an unexpected tool for communication. After having an argument with her daughter, she is deeply shocked when she reads "For despite what some people say, love is not only a sweet feeling bound to come and quickly go away" (Shafak 2010,15), because she had said more or less the same thing to her daughter shortly before reading the sentence. Ella only picked the book because it was her task to read new manuscripts and write reports on them at work, and she even tried to remove the manuscript from those she was supposed to read, since she was too unfamiliar with the setting in thirteenth-century Konya to evaluate the work. But when she is simply struck by the words, she goes on to read that "in many ways the twenty-first century is not that different from the thirteenth century" (Shafak 2010, 15), which seems to reflect her exact thoughts and even frighten her a bit. In her article on the "Rumi Phenomenon," Elene Furlanetto argues that the Sufi poet Rumi is Americanized in Shafak's novel when Rumi and Ella are connected through their sadness, while Rumi's companion, Shams of Tabriz, and Aziz Zahara, the writer of the manuscript Sweet Blasphemy, are connected through their spiritual way of perception (Furlanetto 2013, 205). The term "Americanized" does not mean that Rumi or Shams show something in common with the modern US in an artificial manner; it refers more to similarities between people in the twenty-first century and the thirteenth century, since Ella and Aziz see themselves in the same state of mind as Rumi and Shams. In this case, the language barrier is not as visible as in Aimée's case because Sweet Blasphemy is written in English and Ella does not (unlike Aimée in Argentina) have to learn a new language to read about Rumi. Ella does not understand Rumi's story despite her knowledge of English, though the manuscript is written in English. But when she fully identifies with the messages stated in the book, the 
ideological barrier vanishes. While Stahl creates characters who are supposed to learn and speak different languages, and flower arrangement becomes one of those languages, Sweet Blasphemy is to be seen as a universal link between Rumi, Shams, Ella, and Aziz.

\subsection{Names and identity}

Foreigners sometimes adapt their names to easily get access to a foreign country, hoping to make their names sound more familiar to local people. This phenomenon is also to be seen in Aimée and Aziz, because they change their names in order to adapt: Aimée Levrier would have been called Amy Oleary in the US, and Aziz was born as Craig Richardson in Scotland before he decided to integrate Sufism into his life. On one hand, Aimée's changed name is partially the result of her mother's wish to flee from a dark family secret, since Hanako's husband was not Aimée's biological father and there were conflicts between her and her husband's family in the US. On the other hand, "Aimée Levrier" sounds more poetic and less American than "Amy Oleary," which might help Aimée to feel less foreign in a completely new place. Aud-Kirsti Pedersen argues in his paper "Can Choosing the Form of a Name Be an Act of Identity?" that people tend to want to decide the names of places, and do not feel attached only to the place itself, because the name of a certain place, in this case referring to personal property, is connected with personal thoughts and emotions (Pedersen 2012, 178). After considering the importance of the naming process, it is understandable that Aziz decided to become Aziz Zahara rather than remaining Craig Richardson when he became a Sufi. First, the name "Craig" would not give the impression that he admired Rumi and converted to Islam to find his new life. Since a name plays a crucial role in building personal identity, Aziz has a reason to shape the path of his life by choosing a new name as a Sufi with a sense of belonging. Second, the act of taking a new name is also important for Aziz in terms of individuality because he can set a boundary between his life as a Sufi and his old life with this symbolic act.

By considering the connections mentioned above, it is clear that name, identity, culture, and language are deeply connected with each other. This connection becomes apparent when the characters Aimée and Aziz change their names to adapt themselves to a new cultural environment where unknown languages might be spoken and changing perceptions is necessary. 


\subsection{Language, identity, nation, and otherness as main cultural factors}

One of the most essential elements in a comparison between Fleurs d'un jour and The Forty Rules of Love is the relationship between mother and daughter. Hanako and Aimée stay quite close throughout the novel, though Hanako does not speak at all and Aimée has to take care of her mother because of her muteness and agoraphobia. The daughter seems to play the role of mother for her own parent, which everyone assumes is a burden for the daughter but does not actually affect their friendly relationship seriously. Hanako's symptoms are also caused by her trauma from World War II in Japan, but her special needs do not bother Aimée's husband, an Argentinian doctor of Italian origin, either. Fernando, Aimée's husband, does not see in his mother-in-law someone who is depressed or sad, and he tries to soothe his wife as well as he can, which is extremely helpful for Aimée's personal journey regarding her hidden family history in the US. It is a kind and warm gesture when Fernando explains on the phone how Hanako is doing and what kind of flower arrangement she has created, though he is not capable of describing Hanako's artistic work as thoroughly as his wife demands. At this point, the bond between speechless mother and daughter is clearer because Aimée can even guess her mother's condition from her daily flower arrangement. Having this special bond is not an option for Fernando, since deducing an emotional connection between a flower arrangement and its creator lies beyond his ability. At this point, ikebana fulfils its function as a language, and Fernando is a little lost as someone who does not speak the language.

Homi K. Bhabha argues in The Location of Culture that the term "cultural difference" is constituted through comparison between oneself and others, while the minority create a space to differentiate themselves from the majority (Bhabha 1994, 162). This process is to be understood more as a natural consequence than something that the minority group does on the purpose: Hanako does not have anyone who can relate to her experience regarding her trauma from World War II, and it could be a burden for her if she had to explain her background to others. Her otherness, which differentiates her from her neighbours in Argentina, could be seen as a part of her self-protection since it justifies her silence. The location, in this case Argentina, does not seem to play a significant role in her case, since her physical symptoms and her flower arrangement skills would have put her in a different category than people around her in other countries as well. At this point, Hanako's condition is not only the result of the wartime tragedy in her home town but also partially her choice, since everyone chooses their own way to build a wall for self-protection: In other words, Hanako's life has not been decided entirely by a given cultural environment such as locality or history. She 
has her flowers, daughter, and supportive son-in-law, at least, and seems to have many kind people around her, which gives her a certain sense of security despite many cultural obstacles. Her daughter seems unfazed by her past: the absence of a strong male figure from the family never seems to disturb Aimée, except after her arrival in Buenos Aires as a child who has to circumvent the loss of a wellknown language and her father. Her childhood has not destroyed the potential for a romantic relationship, which is proven through her caring husband Fernando, who supports his wife and mother-in-law as well as he can.

Elif Shafak's approach is slightly different from that of Anna Kazumi Stahl. Stahl's characters are confronted with a painful and sometimes mysterious family history without a dramatic lifestyle change from outside, but almost everyone in The Forty Rules of Love experiences a radical transformation through an interpersonal relationship. After reading Sweet Blasphemy, Ella realizes her life needs a change and decides to stay focused on her newly gained understanding of "love" in order to begin a new, unconventional life.

Shams, who rejects the rules of society and communicates with everyone by using a simple but powerful language, is killed in Sweet Blasphemy. At first, it is unclear if Shams and his provocative behaviour have changed the community after his death. But Rumi, a well-known Sufi poet, discovers an unknown side to himself through the encounter with Shams and, though he is deeply shaken by the tragedy, his new friend's death leads Rumi to discover cultural aspects which he was not aware of. For example, Rumi was even ready to ignore customs which were based on cultural norms and religious ideas. Although Shams stops him and a grave scandal is prevented, this incident is one of the reasons why people hire a killer to kill Shams. While the majority in town sees in Shams a big threat to the community, Shams changes many people's perceptions and decision-making processes. Rose, who belongs to the minority since she is a prostitute and no one respects her, is able to begin a new life after Shams encourages her to forget social boundaries. At first, Rumi sees himself as a scholar and a preacher, but Shams prophesies that Rumi's poetry will change the world, not his famous sermons or lectures. Rumi is devastated when Shams also indicates that they will be separated from each other in the near future and Rumi has to find his own path, while Aladdin cannot hide his jealousy and wishes that his father was more attentive. What Shams said in advance becomes a reality after Shams faces death at the hands of a professional killer and Rumi tries to overcome his sadness through poetry.

Since "the radical alterity of the national culture will create new forms of living and writing” (Bhabha 1994, 166), the changes caused by an encounter with a foreign culture are not to be interpreted as a negative for further development of the nation: the United States of America, which is one of the most powerful 
countries in the world, was built with the support of immigrants and serves as an outstanding example of multiculturalism. While some characters in Sweet Blasphemy find a new way of living and thinking, Ella is also capable of discovering new possibilities which lead her to abandon her family and accompany Aziz on his trip to Konya until his death a year later.

Ella's husband, David, represents a Jewish-American man who is aware of the importance of his own family and the Sabbath as a traditional religious event, but he does not personify an ideal father-figure since he is merely focused on social conventions and his own feelings. Despite the lack of a strong presence for the concept of national borders in Ella's case, which could be explained in terms of a sense of globalism without a clear border between nations, it is interesting to observe Ella, who is able to overcome a boundary created by her inner self. She embraces the sense of universality which connects her all of sudden with a Scottish man, who has converted to Islam and seems to personify the other side of the coin. In other words, Ella already had the potential to overcome boundaries which are mainly caused by factors such as religion and marital conflict; she just needed Aziz to recognize her personal interests even though they were already there. Although Ella's bold decision to follow her heart does not show any visible influence on the further development of a particular country, her attempt to change her life demonstrates that there is a very small difference between a majority group and a minority group: Ella belonged to the majority as a married Jewish-American woman with three children, but as soon as she chooses Aziz over her conventional family life, there are lots of people who see a serious mistake in her brave action.

On closer consideration where multiculturalism is concerned, one could say that no particular language is stated to be important for interpersonal communication by Stahl and Shafak. It is, though, easy to overlook the existence of communication tools in both authors' novels: Aimée and Hanako share ikebana as a common value, and it lays a foundation for their social status, and Aimée can read her mother's state of mind through flower arrangement. It is true that Aimée is confronted with a language boundary when she flies to the US. But, though her English seems unnatural because she thinks in another language at first and translates it word by word into English, there are no serious obstacles caused by her language problem. The scene in question has something in common with the real-life situation in the US, where English is spoken in many different styles and accents.

There are also no visible issues regarding foreign languages between Shams and Rumi because they do not have to learn an unknown language to be able to communicate. But when Shams confronts Rumi with the new concept of belief and God's words in their personal exchange, Rumi becomes aware for the first 
time of his own ability to convince people through his rhetorical art in a rather different way from giving a sermon. Rumi might have been surprised by his new friend's art of speaking, which indirectly prompts him to forget his conventional education and embrace apparently useless concepts like love and philosophy. As Rumi follows this advice and starts writing poems, which makes him a unique artist for his descendants, Rumi and Shams speak of those same poems, albeit in a brutally earnest language. Although they have always spoken the same language in terms of its linguistic classification, Rumi's new rhetorical awareness destroys the boundary between him and Shams, and this "language" provides the feeling of connectedness which is mainly accentuated by Shams' death.

\section{Conclusion}

Having knowledge of a certain language is essential in many cases when it comes to communication. Sometimes, however, even having this knowledge does not prevent misunderstanding in a conversation, which accentuates the fragility of spoken words in general. The protagonist Aimée Levrier in Fleurs d'un jour experiences the difficulty of speaking a foreign language before and during her journey to the US, since she has to choose her words carefully in order not to make any mistakes when she speaks English. This circumstance often leaves her with a feeling of unease, and although she has no problems speaking English for the purpose of her visit, the English words chosen by her are directly translated from Spanish from time to time, and people detect her accent as Cuban or Argentinian.

Alexander Jefremov indicates in "Translating a Translingual Text: Primeros Dias Porteños by Anna Kazumi Stahl” that Anna Kazumi Stahl has to navigate between English, Spanish, and Japanese, and her literary work in Spanish is marked by simplistic grammar and lexis (Jefremov 2016, 112). The autobiographical aspect, which accentuates the similarities between Stahl and Aimée, stands out at this point, since it is widely known that Stahl learned Spanish in her twenties and had to face several obstacles during her learning process. Yet, in the end, Stahl became a successful writer and translator despite such obstacles and (according to Jefremov) some simplistic elements in her written work in Spanish. This connects her with her character, Aimée, who is able to master her tasks herself by using a foreign language.

At first sight, there are no ties between Shafak and Ella Rubinstein in The Forty Rules of Love: they look quite different in terms of nationality, religious belief, and lifestyle. But if one takes a closer look at their revelations, the hidden common feature shared by each author and her main character shines out all of 
sudden. Both of them understand, at a certain point in life, that concepts such as nationality, language, and culture depend on their interpreters and cannot be perceived by everyone in the same way; there is always a certain sense of universality for cosmopolitans such as Ella and Shafak. Ella never thought that she could love a Scottish man who devotes his life to Sufism as a converted Muslim. However, the lessons in Sweet Blasphemy, which lightens her burden in an unexpected way through the wise words of Shams, demonstrate to her that the nature of certain things always stays the same even though many centuries lie between her and Shams. This universality reflects Shafak's own personal background: she speaks in an interview of certain people leading the "life of a foreigner in their own homeland" and says the following about herself: "In Turkey, in early childhood, there was a time when I found myself moving between two cities, two grandmothers, each in utterly different worlds" ("Migrations" 2003, 56). Ella did not have the opportunity to have such experiences in her childhood, but her encounter with an unknown manuscript about a completely unfamiliar theme changes everything, and she explores different worlds all of a sudden without going anywhere first.

According to Julia Kristeva, there is the process of identifying constituted by historical characteristics and there is the loss of identity in the process of cultural identification (see Bhabha 1994, 153). The protagonists in Fleurs d'un jour and The Forty Rules of Love also experience a sense of historical identity which serves as a form of personal standard, although Ella seems to be more attached to it than Hanako and her daughter. The loss of identity can be interpreted in more than one way. On the one hand, an individual may focus on a given cultural context too strongly and ignore their perception, which differs from cultural expectations. But, on the other hand, one can also be freed of the identity which is dictated by a society: this happens in the two literary works which were the main topic of this article, since the protagonists do not connect certain cultural aspects with their identities and embrace instead versatility regarding culture and language.

\section{Works cited}

Aizenberg, Edna. "Ethnos Meets Eros on the River Plate: Marcelo Birmajer, Sylvia Molloy, Anna Kazumi Stahl." Studies in 20th \& 21st Century Literature 29.2 (2015): 205-221.

Bhabha, Homi K. The Location of Culture. London and New York: Routledge, 1994.

Furlanetto, Elena. “The 'Rumi Phenomenon' between Orientalism and Cosmopolitanism: The Case of Elif Shafak's The Forty Rules of Love." European Journal of English Studies 17.2 (2013): 201-213.

Jefremov, Alexander. “Translating a Translingual Text: Primeros Dias Porteños by Anna Kazumi Stahl." Spec. issue of Colloquy: Text, Theory, Critique 32 (2016): 109-126. 
“Migrations: A Meridians Interview with Elif Shafak." Meridians: Feminism, Race, Transnationalism 4.1 (2003): 55-85.

Moriyama, Marie, and Megumi Moriyama. "A Comparison between Asymmetric Japanese Ikebana and Symmetric Western Flower Arrangement." Forma 14 (1999): 355-361.

Pedersen, Aud-Kirsti. "Can Choosing the Form of a Name Be an Act of Identity?" Oslo Studies in Language 4.2 (2012): 167-182.

Shafak, Elif. The Forty Rules of Love. London: Penguin, 2010.

Stahl, Anna Kazumi. Flores de un solo día. Barcelona: Editorial Seix Barral, 2002.

Stahl, Anna Kazumi. Fleurs d'un jour. Trans. Isabelle Gugnon. Paris: Seuil, 2005.

Youngmi Kim is from South Korea and holds bachelor's and master's degrees in Comparative Literature and Theatre, Film, and Media Studies from the University of Vienna, Austria. She is now enrolled in a doctoral program in Comparative Literature at Seoul National University. 
